\title{
Watching space
}

\author{
Helen Macdonald clinical editor
}

The BMJ

The happiest doctors in Britain may be found north of the border from now. It's April, Scotland has escaped the stranglehold of the quality outcomes framework (QOF), and Margaret McCartney waves it off (doi:10.1136/bmj.i1763). "What will happen next is a great big uncontrolled experiment, with England versus Scotland." Among some of QOF's more "perverse incentives" McCartney writes, were points for asking whether even patients who had never smoked had started in the past five years-a clumpy question to weave into a consultation. I doubt McCartney is alone in waving good riddance to QOF, but it remains to be seen exactly what will move into the space it vacates.

Space, specifically life on Mars, is the stuff of science fiction, but doctors are thinking about how to help humans survive there. In BMJ Careers Sheyna Gifford is interviewed about her three year expedition to Mars, simulated from a volcano in Hawaii (http://careers.bmj.com/careers/advice/Life_on_Mars). That "all the fluids in the body gravitate upwards and the heart assumes a balloon-like configuration" sounds worrying, combined with the expected muscle atrophy and low bone density in low gravity. Gifford, an astrophysicist and expedition doctor, cares for simulation astronauts on the NASA funded Hi-Seas programme, where she says her role has forced her to "get back to the basics of what medicine is really about: looking, listening, feeling, asking, watching and waiting."
Watching and describing form the basis of research documenting brain abnormalities in Brazilian babies born with microcephaly in 2015, after presumed infection with Zika virus in utero. It's unusual for The BMJ to publish case series, but we need more data on the association between maternal infection and pregnancy outcomes. These new data from Maria de Fatima Vasco Aragao and colleagues (doi:10.1136/bmj.i1901) appear in The BMJ this week alongside old and partly unpublished data on dietary fat gathered between 1968 and 1973 (doi:10.1136/ bmj.i1246). Does replacement of saturated fat with vegetable oils reduce coronary heart disease and death? Ask Ramsden and colleagues. Residents of US nursing homes and state mental hospitals were randomised to a diet rich in polyunsaturated fat and compared with a control group with a diet high in saturated fat.

In an accompanying editorial (doi:10.1136/bmj.i1512) J Lennert Veerman says that the meta-analysis casts doubt on dietary advice to the general population to switch from saturated to polyunsaturated fat. Polyunsaturates reduced the surrogate marker of cholesterol, which Veerman explains was "paramount in decisions about dietary guidelines." But he writes that Ramsden's team found that polyunsaturates "did not reduce mortality: in fact participants in the intervention group had a higher mortality than controls."

He awaits further clarification, so watch this space. 